\title{
HOXC6 regulates the antitumor effects of pheophorbide a-based photodynamic therapy in multidrug-resistant oral cancer cells
}

\author{
SOO-A KIM ${ }^{1}$, MI RHA LEE ${ }^{3}$, JUNG-HOON YOON $^{2}$ and SANG-GUN AHN ${ }^{3}$ \\ ${ }^{1}$ Department of Biochemistry, Oriental Medicine, Dongguk University, Gyeongju 780-714; \\ ${ }^{2}$ Department of Oral and Maxillofacial Pathology, College of Dentistry, Wonkwang University, Daejeon 302-120; \\ ${ }^{3}$ Department of Pathology, College of Dentistry, Chosun University, Gwangju 501-759, Republic of Korea
}

Received August 30, 2016; Accepted November 2, 2016

DOI: $10.3892 /$ ijo.2016.3766

\begin{abstract}
Photodynamic therapy (PDT) has been considered to be a possible candidate approach for the treatment of multidrug-resistant (MDR) cancer. To investigate the photocytotoxicity of pheophorbide a-based PDT on MDR cells, the intracellular pathways were studied using the human oral cancer FaDu cell line and its paclitaxel-selected subline FaDu-PTX. Pheophorbide a (Pa)-PDT induced significant photocytotoxicity in both FaDu and FaDu-PTX cell lines with cell apoptosis greater in FaDu cells compared to FaDu-PTX cells. We found that HOXC6 and MDR-1 expression was strongly detected in FaDu-PTX cells compared to FaDu cells. Intriguingly, Pa-PDT effectively reduced HOXC6 and MDR-1 expression in FaDu-PTX cells. The siRNA for HOXC6 can inhibit the intracellular MDR-1 levels in FaDu-PTX cells and induce the phototoxic effects of Pa-PDT. Furthermore, our in vivo studies showed that the Pa-PDT and HOXC6 siRNA significantly reduce the growth of FaDu-PTX xenograft tumors in $\mathrm{C} 3 \mathrm{H}$ mice compared with control- and PTX-treated tumors. Histopathology was also used to confirm this antitumor effect. Pa-PDT may be a potential therapeutic modality for multidrugresistant cancer, and Hoxc6, as a possible contributor to MDR, may reduce the therapeutic potential in multidrug-resistant oral malignancies.
\end{abstract}

\section{Introduction}

Multidrug resistance (MDR) is considered to be a major contributor to failure of chemotherapy in treating cancer (1-3). Among cancer therapies, chemotherapy can palliate symptoms and prolong life for some cancer patients. However, cancer cells can have intrinsic or acquired resistance after treatment with chemotherapeutic drugs leading to the development of

Correspondence to: Professor Sang-Gun Ahn, Department of Pathology, College of Dentistry, Chosun University, Gwangju 501-759, Republic of Korea

E-mail:ahnsg@chosun.ac.kr

Key words: HOXC6, multidrug resistance, photodynamic therapy, pheophorbide a, oral cancer
MDR. MDR attenuates the efficacy of anticancer drugs and results in treatment failure for cancer $(2,4)$. The phenomenon of multidrug resistance (MDR) in cancer is associated with the overexpression of the ATP-binding cassette (ABC) transporter proteins, including multidrug resistance-associated protein 1 (MRP1), breast cancer resistance protein (BCRP) and P-glycoprotein (5-8). Additionally, the genetic alterations of several resistance proteins, including caveolin-1 and HOXC6, have been associated with one of the major processes that characterize MDR development in many cancers $(9,10)$. Although a clear association has been established between MDR and genetic alterations, the mechanism by which multidrug resistance develops in oral cancer has not yet been fully elucidated.

Photodynamic therapy (PDT) uses tumor-selective photosensitizers and subsequent activation by a specific wavelength of light to generate reactive oxygen species. PDT has been used increasingly in the treatment of various cancers $(11,12)$. PDT has been considered to be an alternative for treatment of resistant cancers because its mechanism is completely different from that of conventional chemotherapy (11). In fact, some studies have showed that PDT is reported to inhibit MDR cancers through different cell death pathways and that its effectiveness is dependent on the types of cancer cell lines and photosensitizers used, including mesoporphyrin, phthalocyanines and photofrin (13-15). Recently, we synthesized pheophorbide a $(\mathrm{Pa})$ by removing a magnesium ion and a phytyl group from chlorophyll-a. Our studies reported that Pa-based PDT can effectively inhibit tumor cell proliferation in several cancer cells, including skin and head and neck cancer (16-18). Other research groups reported that Pa-based PDT can effectively inhibit tumor cell proliferation in hepatocellular carcinoma $(19,20)$, colon cancer $(21)$, pigmented melanoma (22) and breast adenocarcinoma (23); however, its therapeutic potential in oral cancer (especially instances of MDR) has not been fully investigated. It is therefore, necessary to focus on the search for strong therapeutic candidates against MDR oral cancer that utilize PDT.

It is known that the HOX family member HOXC6 is associated with several human carcinomas, including gastrointestinal, breast, lung and prostate. HOXC6 is overexpressed in osteosarcomas and medulloblastomas (24-28). In previous studies, HOXC6 was shown to play an important role in several 
cellular events through the regulation of its functional biological targets such as bone morphogenic protein 7, fibroblast growth factor receptor 2 and platelet-derived growth factor receptor, as well as the PI3K/AKT, Notch and Wnt signaling pathways (29-33). In addition, we found that HOXC6 is an important mechanism of the multidrug resistance pathway via regulation of Bcl-2 and MDR-1 (10,34). Although HOXC6 is critical for various regulated cellular processes and is correlated with the progression of multidrug resistance, the function of HOXC6 in oral cancer is largely unknown.

The present study investigated the efficacy and pathway of Pa-PDT-based HOXC6 sensitization to resolve multidrug resistance. Here, our data provided novel evidence that MDR-1 was a direct regulatory target of HOXC6. These data suggest a potential role for Pa-PDT-mediated HOXC6 inhibition in the regulation of chemotherapeutic drug resistance.

\section{Materials and methods}

Cell culture. FaDu human pharynx squamous cell carcinoma (SCC) was purchased from the American Type Culture Collection (ATCC; Rockville, MD). FaDu-PTX cells were created by exposing wild-type FaDu cells to increasing concentrations of paclitaxel for more than 10 months. The FaDu and FaDu-PTX cell lines were incubated in Dulbecco's modified Eagle's medium (DMEM) containing 10\% fetal bovine serum (FBS) and 100 units $/ \mathrm{ml}$ penicillin-streptomycin (Invitrogen, Carlsbad, CA, USA) at $37^{\circ} \mathrm{C}$ in an atmosphere containing $5 \% \mathrm{CO}_{2}$.

Cell proliferation assay. Cells were plated in 12-well plates at a density of $5 \times 10^{4}$ cells/well plate. A total of $100 \mu \mathrm{l}$ (3-(4,5-dimethylthiazol-2-yl)-2,5-diphenyltetrazolium bromide) MTT reagent (Sigma-Aldrich) was added to each well. After a 2-h incubation at $37^{\circ} \mathrm{C}$, the supernatant was aspirated, and formazan crystals were dissolved in $500 \mu \mathrm{l}$ dimethyl sulfoxide (DMSO) at $37^{\circ} \mathrm{C}$ for 15 min under gentle agitation. The absorbance per well was measured at $570 \mathrm{~nm}$ using a multimode ELISA reader (Beckman Coulter, Inc., Wals-Siezenheim, Austria).

Reverse transcription quantitative PCR (RT-qPCR) analysis. Quantitative real-time PCR was performed using SYBRGreen (Applied Biosystems, Foster City, CA, USA). PCR runs and fluorescence detection were performed in a Rotor-Gene 6000 Real-Time PCR system (Corbett Research, Sydney, NSW, Australia). On the basis of HOXC6 and MDR-1, two pairs of gene-specific primers were designed. The reaction mixture contained $10 \mathrm{ng}$ of cDNA diluted in $2.5 \mu \mathrm{l}$ DEPCtreated water, $5 \mu 1$ Power SYBR-Green PCR Master Mix (2X; Applied Biosystems) and $2 \mu \mathrm{l}$ of gene-specific primers (final concentration $50 \mathrm{nM}$ each) in a final reaction volume of $10 \mu \mathrm{l}$. The sequences of the real-time PCR primers were as follows: HOXC6, forward 5'-CACCGCCTATGATCCAGTGAGG CA-3' and reverse 5'-GCTGGAACTGAACACGACATTC TC-3'; MDR-1, forward 5'-GACTGTCAGCTGCTGTCTGG GCAA-3' and reverse 5'-GCCAAGACCTCTTCAGCTAC TGC-3'; glyceraldehyde 3-phosphate dehydrogenase, forward 5'-AGCCAAAAGGGTCATCATCTCTGC-3' and reverse 5'-GCATTGCTGATGATCTTGAGGCTG-3'. The cycling conditions were as follows: denaturation at $95^{\circ} \mathrm{C}$ for $10 \mathrm{~min}$ followed by 40 cycles of $95^{\circ} \mathrm{C}$ for $20 \mathrm{sec}, 58^{\circ} \mathrm{C}$ for $20 \mathrm{sec}$ and $70^{\circ} \mathrm{C}$ for $20 \mathrm{sec}$.

Measurement of intracellular ROS. After Pa-PDT, the cells were washed twice with phosphate-buffered saline (PBS) and incubated in a medium containing $10 \mu \mathrm{M} 2^{\prime} 7^{\prime}$-dichlorofluorescein diacetate and $\mathrm{H}_{2} \mathrm{DCFDA}$ (Invitrogen) at $37^{\circ} \mathrm{C}$ in an atmosphere containing $5 \% \mathrm{CO}_{2}$ for $30 \mathrm{~min}$. The fluorescence was analyzed immediately using a multimode ELISA reader (Beckman Coulter).

Flow cytometric cell cycle analysis and Annexin V-FITC/ $P I$ staining. For cell cycle analysis, FaDu and FaDu-PTX cells were fixed in chilled $70 \%$ methanol for $1 \mathrm{~h}$ at $4^{\circ} \mathrm{C}$ and stained with propidium iodine (PI) solution (100 $\mu \mathrm{g} / \mathrm{ml}$ RNase and $10 \mu \mathrm{g} / \mathrm{ml} \mathrm{PI}$ in PBS) at $37^{\circ} \mathrm{C}$ for $30 \mathrm{~min}$. In addition, the cells were stained using the Vybrant apoptosis assay kit (Molecular Probes) followed by labeling with Alexa Fluor ${ }^{\circledR}$ 488 Annexin V and PI for apoptosis analysis. Data acquisition and analysis were performed using the Cell Lab Quanta ${ }^{\mathrm{TM}} \mathrm{SC}$ flow cytometer and software (Beckman Coulter, Inc., Miami, FL, USA).

Western blot analysis. The cells were treated with Pa-PDT for $24 \mathrm{~h}$. The cells were then washed with PBS and harvested in lysis buffer. Samples containing equal amounts of protein were loaded onto individual lanes of an SDS-polyacrylamide gel for electrophoresis and subsequently transferred onto a polyvinylidene difluoride membrane. The membranes were blocked and then incubated with antibodies. Antibodies against p-ERK1/2, p-AKT, p-p70S6K, CDKs, cyclin B and cyclin D1 were purchased from Cell Signaling Technology (Beverly, MA, USA), whereas HOXC6, Notch1, Notch-4, MDR-1 and $\beta$-actin antibodies were purchased from Santa Cruz Biotechnology (Santa Cruz, CA, USA). For detection, an ECL kit (Amersham Biosciences Life Sciences) was used according to the manufacturer's instructions.

Photodynamic therapy. The PDT irradiation light source was a light-emitting diode (LED; 613-645 nm; Philips Luxeon Lumileds, San Jose, CA, USA). The cells (1x10 $/$ well) were pre-incubated with $\mathrm{Pa}(0.2 \mu \mathrm{M})$ in complete growth medium in the dark for $2 \mathrm{~h}$. For the subsequent experiments, the cells were irradiated at $1.2 \mathrm{~J} / \mathrm{cm}^{2}$. For the control group, the cells were incubated in the same medium with neither Pa nor light.

siRNA interference assay. siRNA constructs for HOXC6 were obtained in the form of Silencer ${ }^{\circledR}$ Select Validated siRNA (Applied Biosystems). The sense sequence of the HOXC6 siRNA was 5'-CUC GUU CUC GGC UUG UCU A (dTdT)-3' and the antisense sequence was 5'-UAG ACA AGC CGA GAA CGA G (dTdT)-3'. Cells were transfected with siRNA (20 nM) using Lipofectamine 2000 RNAiMAX transfection reagent (Invitrogen) according to the manufacturer's instructions. The cells were harvested $48 \mathrm{~h}$ after transfection. Total cell lysates were separated by SDS-PAGE and analyzed by western blot analysis as described above.

In vivo study in $\mathrm{C} 3 \mathrm{H}$ mice. FaDu-PTX cells were transfected with either HOXC6 siRNA (20 nM) for $48 \mathrm{~h}$ or Pa-PDT 

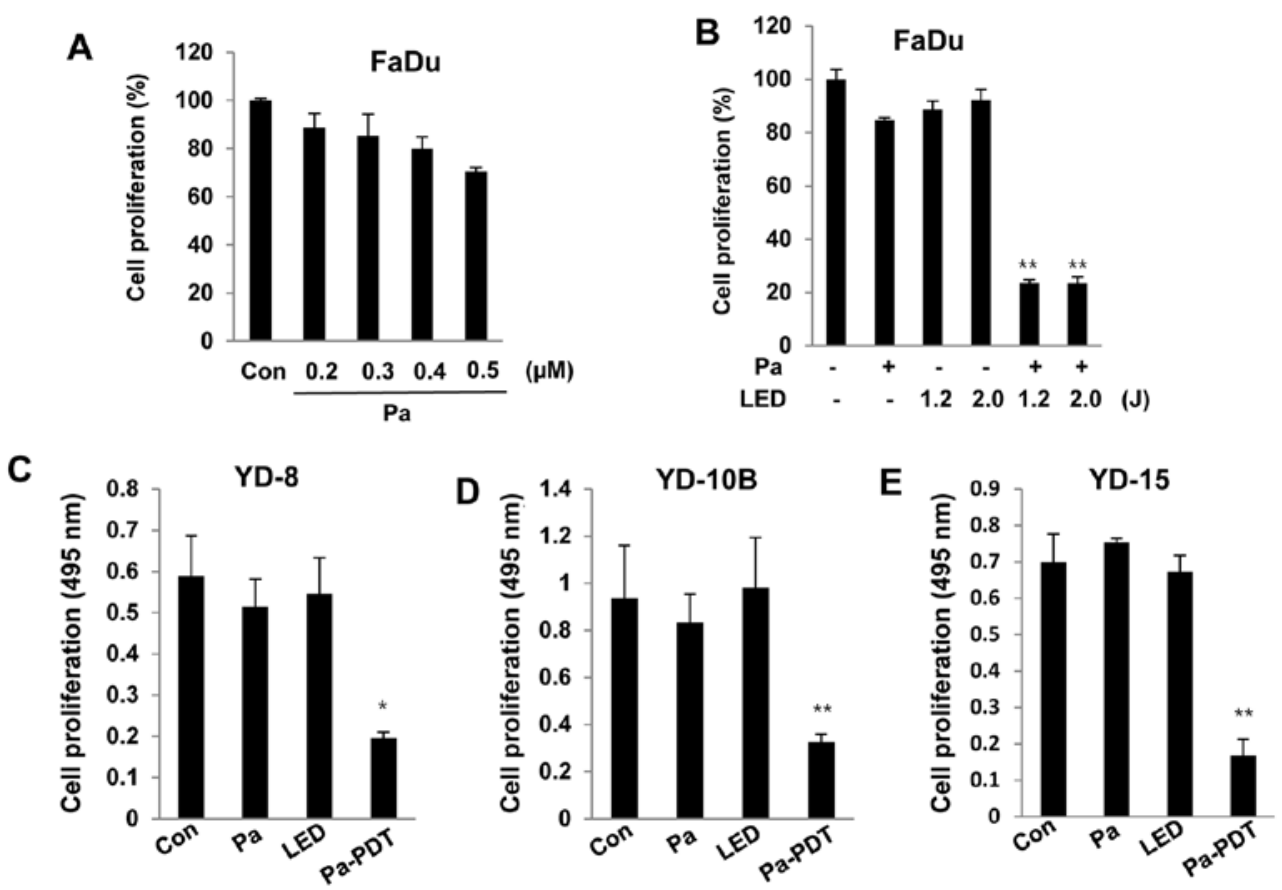

Figure 1. Pa-PDT-induced cytotoxicity in oral cancer. (A) Pa dose-dependent changes in cell proliferation. FaDu cells were treated with pheophorbide a at the indicated concentration for $24 \mathrm{~h}$. Cell proliferation was assessed by the MTT assay, as described in Materials and methods. (B) The effect of Pa-PDT on FaDu cell growth. FaDu cells were preincubated with $\mathrm{Pa}(0.2 \mu \mathrm{M})$ for $2 \mathrm{~h}$ and exposed to light irradiation at different light fluences $\left(1.2 \mathrm{or} 2.0 \mathrm{~J} / \mathrm{cm}^{2}\right)$. (C-E) The effects of Pa-PDT on YD-8, YD-10B and YD-15 oral cancer cells. YD-8, YD-10B and YD-15 cells were preincubated with $0.2 \mu \mathrm{M}$ Pa for $2 \mathrm{~h}$ and then illuminated $\left(1.2 \mathrm{~J} / \mathrm{cm}^{2}\right)$. The results represent the mean \pm SEM of three separate experiments, each of which was performed in triplicate. ${ }^{*} \mathrm{P}<0.05,{ }^{* *} \mathrm{P}<0.01$ compared to untreated control.

$\left(0.2 \mu \mathrm{M}, 1.2 \mathrm{~J} / \mathrm{cm}^{2}\right)$ for $24 \mathrm{~h}$. Cells $\left(3 \times 10^{6}\right.$ per mouse) were injected subcutaneously into the left flank of 4-week-old male immunocompetent $\mathrm{C} 3 \mathrm{H}$ mice (Samtaco Bio, Sungnam, Korea) in each group $(n=10)$. Two weeks later, the tumor volume was measured by caliper and calculated by the formula $\mathrm{V}=\left(a b^{2}\right) / 2$, in which $\mathrm{a}$ is the longest diameter and $\mathrm{b}$ is the shortest diameter of the tumor. All mice were euthanized on day 14, and the tumors were removed, scaled, and subjected to further analysis. Immunohistochemistry of tumors and H\&E staining were performed as previously described (18).

Statistical analysis. Statistical analysis was performed with the data obtained from three independent experiments. The data are presented as the mean \pm SEM. A P $<0.05$ was considered statistically significant.

\section{Results}

Antitumor effect of Pa-PDT on human oral cancer cells. To examine the cytotoxicity of $\mathrm{Pa}, \mathrm{FaDu}$ cells were incubated with various concentrations $(0.2$ to $0.5 \mu \mathrm{M})$ of $\mathrm{Pa}$ for $24 \mathrm{~h}$ in the dark. Cell viability was measured using an MTT assay. As shown in Fig. 1A, significant cytotoxicity was not observed in $\mathrm{FaDu}$ cells at $0.2 \mu \mathrm{M} \mathrm{Pa}$. FaDu cells were pre-treated with $0.2 \mu \mathrm{M} \mathrm{Pa}$ for $2 \mathrm{~h}$, followed by photoactivation with 1.2 or $2.0 \mathrm{~J} / \mathrm{cm}^{2}$ of LED. Cell proliferation was strongly decreased after the Pa-PDT treatment. In addition, Pa-PDT also induced significant cytotoxicity in other human YD-8, YD-10B and YD-15 oral cancer cell lines under the same conditions (Fig. 1C-E). These results demonstrated that Pa-PDT exerts an antiproliferative effect on human oral cancer cells.
Pa-PDT inhibits the growth of paclitaxel-resistant FaDu-PTX cells. To examine the effects of Pa-PDT on MDR, FaDu-PTX cells were pre-incubated with various concentrations of $\mathrm{Pa}$ for $2 \mathrm{~h}$ followed by photoactivation with $1.2 \mathrm{~J} / \mathrm{cm}^{2}$ of light. Cell proliferation was determined using an MTT assay. As shown in Fig. 2A, we found that these cell lines exhibited no significant decrease in cell proliferation due to either $\mathrm{Pa}$ or light alone. However, significant cytotoxicity was observed in FaDu-PTX cells after Pa treatment $(0.05-0.2 \mu \mathrm{M})$ in a dosedependent manner, with $\mathrm{IC}_{50}$ values of $\sim 0.05$ and $0.1 \mu \mathrm{M}$ in the FaDu and FaDu-PTX cells, respectively. In FaDu-PTX cells, Pa doses of $0.2 \mu \mathrm{M}$ with LED $\left(1.2 \mathrm{~J} / \mathrm{cm}^{2}\right)$ resulted in cell growth inhibition rates of $70.7 \%$ at $24 \mathrm{~h}$ (Fig. 1A). The effects of Pa-PDT on cell cycle distribution were investigated by flow cytometry. Compared with the untreated control, Pa-PDT treatment caused a reduction of the G1/S phase population and an increase of the G2/M population in both $\mathrm{FaDu}$ and FaDu-PTX cells (Fig. 2B). Western blot analysis was then used to determine whether $\mathrm{G} 2 / \mathrm{M}$ arrest was associated with CDKs. The expression level of CDK1 protein was found to be downregulated after Pa-PDT treatment in FaDu and FaDu-PTX cells whereas that of CDK2 was shown to be downregulated in FaDu cells and undetectable in FaDu-PTX cells (Fig. 2C).

Pa-PDT induces apoptosis in FaDu-PTX cells. We examined that ROS production can be correlated with the Pa-PDT mediated cell proliferation. The levels of ROS were lower following Pa-PDT in FaDu-PTX cells than in FaDu cells (Fig. 3A). We quantified apoptosis by fluorescence microscopy and flow cytometry using the Annexin V-FITC/PI double staining assay. As shown in Fig. 3B, the incubation of cells 

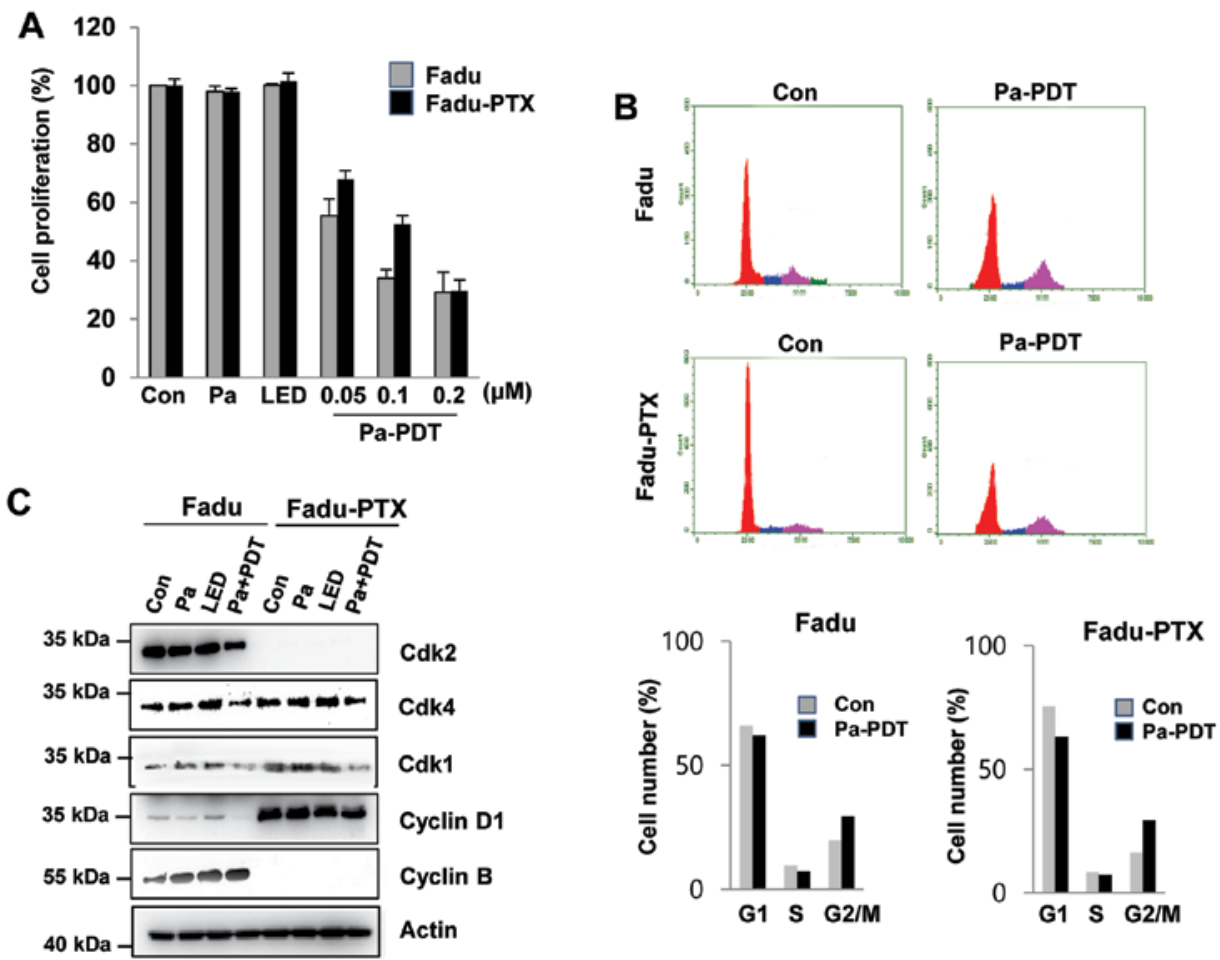

Figure 2. In vitro cytotoxicity of Pa-PDT in paclitaxel-resistant $\mathrm{FaDu}(\mathrm{FaDu}-\mathrm{PTX})$ cells. (A) FaDu-PTX cells were incubated with increasing concentrations of $\mathrm{Pa}$ for $2 \mathrm{~h}$ and exposed to light illumination $\left(1.2 \mathrm{~J} / \mathrm{cm}^{2}\right)$ and subsequently incubated for $24 \mathrm{~h}$. Cell survival was then assessed by MTT assay $24 \mathrm{~h}$ after treatment. The results are presented as the mean \pm SD of three independent experiments. (B) For cell cycle analysis, FaDu and FaDu-PTX cells were harvested at $24 \mathrm{~h}$ after Pa-PDT treatment, fixed and stained with PI $(10 \mu \mathrm{g} / \mathrm{ml}, 30 \mathrm{~min})$. The stained cells were analyzed by flow cytometry, and the percentage of the cell population in the G1, S and G2/M phases are shown in the bar graph. (C) The effect of Pa-PDT on cell cycle regulatory protein expression. FaDu and FaDu-PTX cells were treated with Pa-PDT for $24 \mathrm{~h}$ and assessed by western blot analysis.
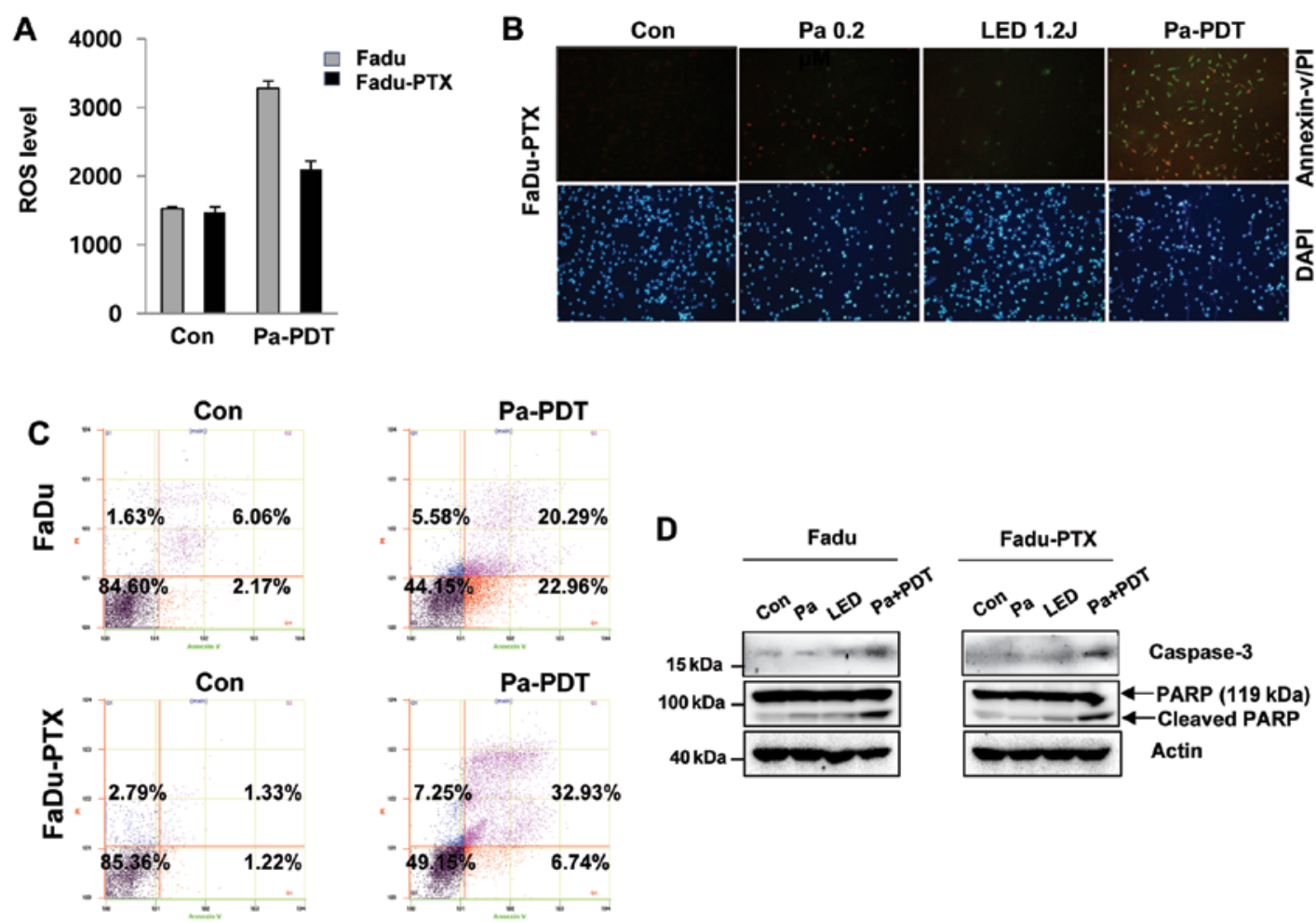

Figure 3. Pa-PDT induces apoptosis in FaDu-PTX cells. (A) Effect of Pa-PDT on reactive oxygen species (ROS) production in FaDu and FaDu-PTX cells. (A) The cells were incubated with $0.2 \mu \mathrm{M}$ Pa followed by exposure to $1.2 \mathrm{~J} / \mathrm{cm}^{2}$ of light. The quantitative amount of ROS production was measured using the scanning multimode ELISA reader. (B and C) Apoptotic cells were quantified using fluorescence microscopy and flow cytometric analysis. FaDu-PTX cells were treated with $0.2 \mu \mathrm{M}$ Pa for $2 \mathrm{~h}$ and irradiated with $1.2 \mathrm{~J} / \mathrm{cm}^{2}$. Annexin V-positive apoptotic cells were analyzed by fluorescence microscopy and flow cytometric analysis after staining with Annexin V/PI. (D) The effect of Pa-PDT on caspase-3 and PARP activity. The cells were treated with Pa-PDT, and cell lysates were subjected to western blot analysis using antibodies against cleaved caspase-3 and PARP. 

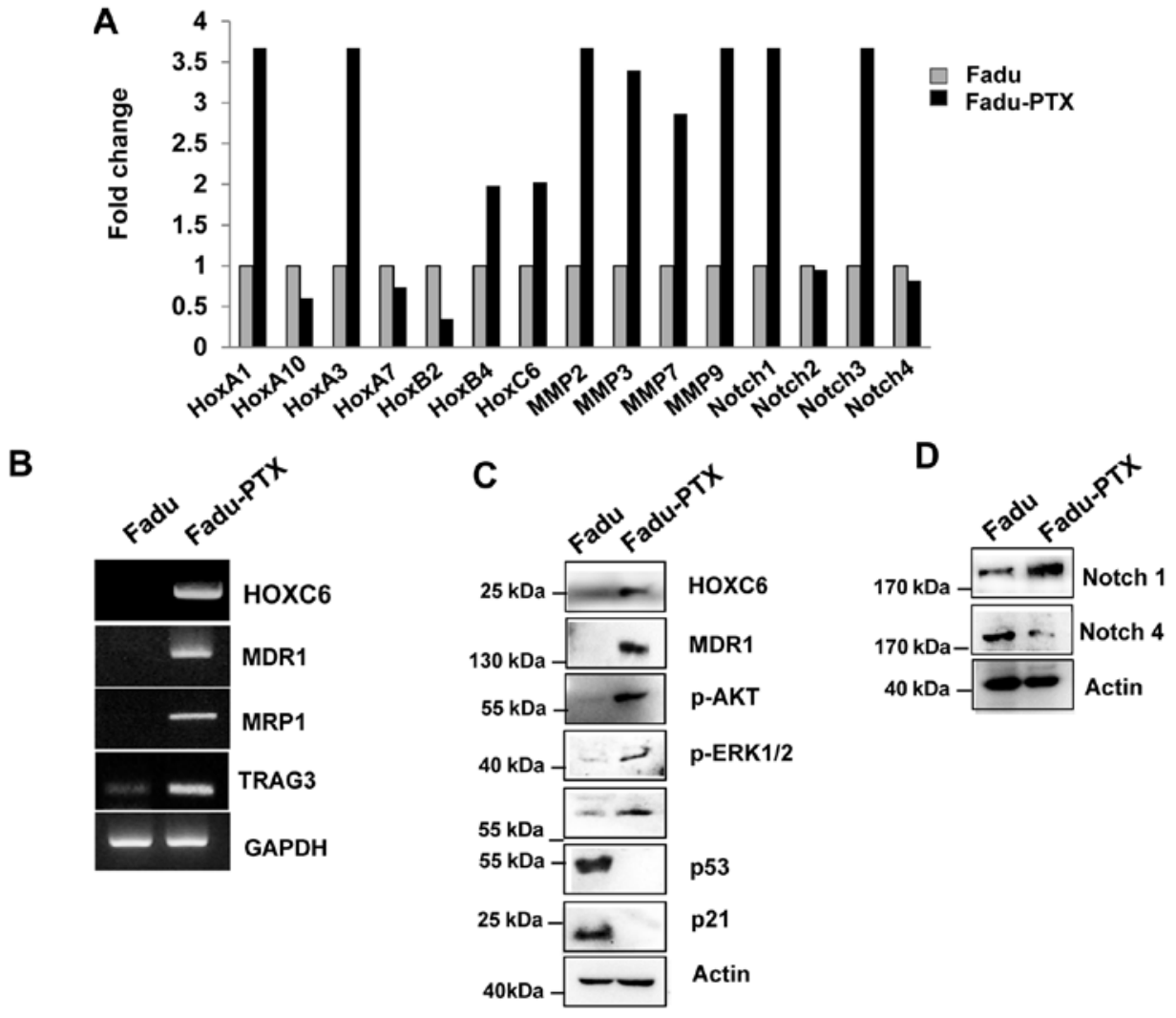

Figure 4. RT-qPCR validation of gene array data in FaDu and FaDu-PTX cells. FaDu-PTX cells were maintained with paclitaxel (400 nM), and the RNA samples used for the qPCR analysis were independent of those used with the SYBR-Green qPCR. (A) Genes that were both upregulated and downregulated as observed in the qPCR array were chosen to validate the MDR cancers. (B) Verification of the qPCR profiling results. HOXC6, Mdr-1, Mrp-1 and Trag-3 mRNA expression was verified by RT-PCR in FaDu and FaDu-PTX cells. (C and D) Protein expression was verified by western blot analysis in FaDu and FaDu-PTX cells. Blots were incubated with primary antibodies to HOXC6, Mdr-1, Notch and Notch-4 as well as $\beta$-actin (loading control).

with Annexin V-FITC/PI showed an increase in green fluorescence after Pa-PDT treatment in FaDu-PTX cells. Similarly, a significant number of apoptotic cells $(39.8 \%)$ was detected in FaDu-PTX cells after Pa-PDT treatment, whereas $43.3 \%$ apoptotic-positive cells were detected in FaDu cells (Fig. 3C). Consistent with this observation, caspase-3 activity were also detected in FaDu and FaDu-PTX cells treated with Pa-PDT. In addition, the cleaved form of PARP was increased by Pa-PDT treatment in both cells (Fig. 3D).

RT-qPCR validation of selected MDR related genes. To validate the MDR results by reverse transcription quantitative PCR (RT-qPCR), we primarily assayed the expression of HOXA1, HOXA10, HOXA3, HOXA7, HOXB4, HOXC6, MMP-2, MMP-3, MMP-7, MMP-9, Notch-1, Notch-2, Notch-3 and Notch-4 in FaDu and FaDu-PTX cells. Ten of the 15 genes examined were upregulated and 3 were downregulated (Fig. 4A). Of these, 10 genes were altered by $>2$-fold, including 7 that were altered by $>3$-fold. As we previously confirmed the aberrant expression of one of the candidates (HOXC6) in multidrug resistance cancer (10), we evaluated the expression of the other HOX genes, HOXA1, HOXA10 and HOXB4, using AccuPower ${ }^{\circledR}$ qPCR assays in FaDu-PTX cells and comparing the values with those from FaDu cells. Significant upregulation of MMP-2, -3, -7, -9, Notch-1 and Notch-3 was observed in FaDu-PTX cells compared to FaDu cells. RT-qPCR analysis demonstrated that the transcription levels of drug resistance-associated genes was increased in FaDu-PTX cells.

To confirm these data, we performed RT-PCR and western blot analysis. HOXC6, MDR-1, MRP1 and taxol resistanceassociated gene 3 (TRAG3) mRNA was strongly expressed in FaDu-PTX cells but weakly expressed in FaDu cells (Fig. 4B). Western blot results demonstrated that, compared with the FaDu cells, the protein levels of HOXC6 and MDR-1 were also increased. According to previous studies, the chemotherapeutic resistance was also attributed to PI3K/AKT/mTOR and Notch pathway activation (35-37). Western blot analysis showed that phosphorylated p-Akt, p-p70S6K, p-ERK and Notch-1 levels were significantly induced in FaDu-PTX cells compared to FaDu cells (Fig. 4C and D). In addition, a previous study showed that p53/p21 is involved in the pathway conferring resistance to paclitaxel (38). However, we found that p53 and p21 levels were unchanged in FaDu-PTX cells.

Expression of HOXC6 and MDRl in Pa-PDT-treated FaDu-PTX cells. To further elucidate the underlying mechanisms of Pa-PDT in FaDu-PTX cells, we assessed the levels of HOXC6 and MDR-1, both of which play a crucial role in MDR. Western blotting revealed that Pa-PDT caused a decrease in the expression of HOXC6 in a dose-dependent manner (Fig. 5A), and the expression of HOXC6 was reduced at $6 \mathrm{~h}$ in both $\mathrm{FaDu}$ and FaDu-PTX cells (Fig. 5B and C). The inhibition of MDR-1 expression was clearly observed at $6 \mathrm{~h}$ after Pa-PDT treatment 
A FaDu-PTX
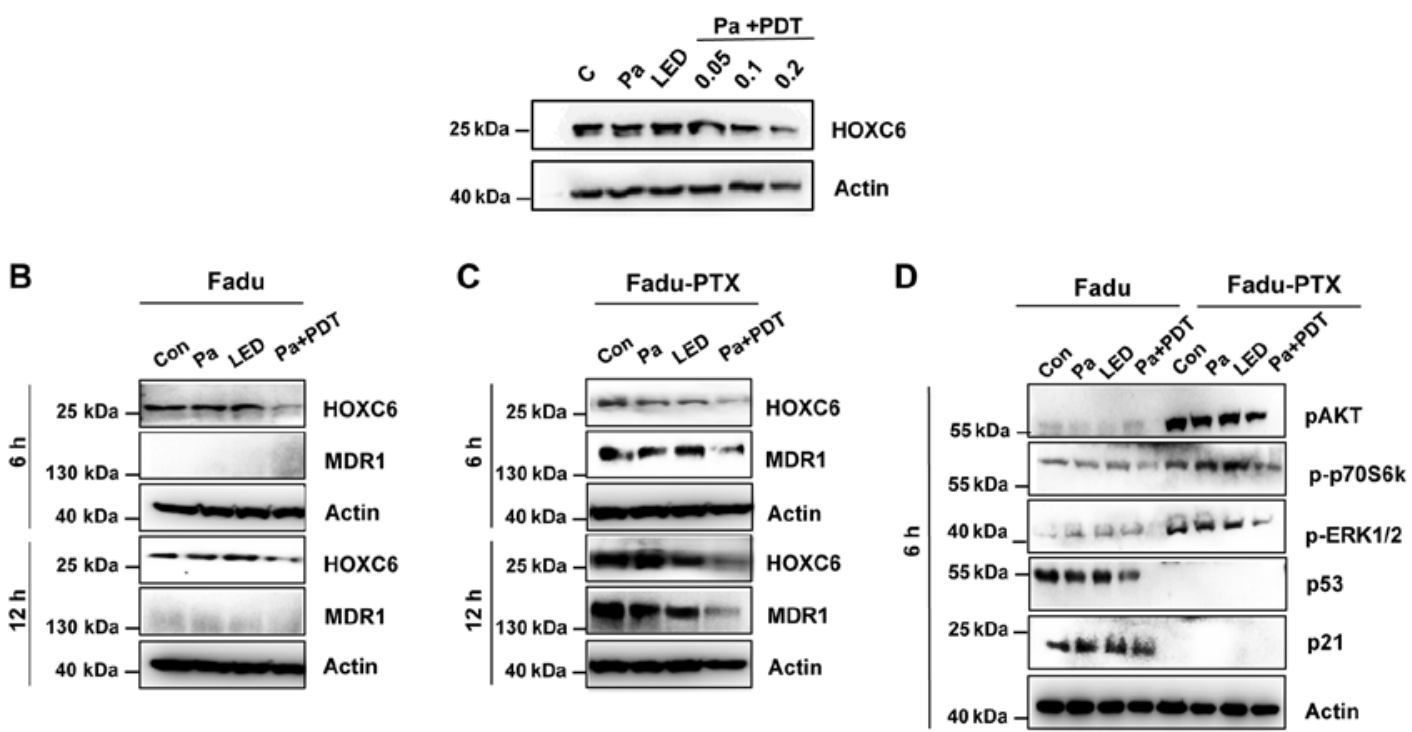

Figure 5. Pa-PDT inhibits the expression of HOXC6 and MDR-1 in FaDu and FaDu-PTX cells. (A) The effect of dose-dependent Pa-PDT on HOXC6 expression. FaDu-PTX cells were pre-treated with pheophorbide a at the indicated concentration for $2 \mathrm{~h}$ and exposed to light illumination $\left(1.2 \mathrm{~J} / \mathrm{cm}^{2}\right)$. HOXC6 was assessed by western blot analysis (B and C). The effects of Pa-PDT on HOXC6 and MDR-1 expression. The cells were treated with Pa-PDT for either 6 or $12 \mathrm{~h}$, and the levels of HOXC6 and MDR-1 were measured by western blotting. (D) The regulation of the p53/p21 and Akt/mTOR signaling pathways after Pa-PDT treatment. The cells were treated with Pa-PDT $\left(0.2 \mu \mathrm{M}, 1.2 \mathrm{~J} / \mathrm{cm}^{2}\right)$ for the indicated time periods and subjected to western blotting. Actin was used as a loading control.

A

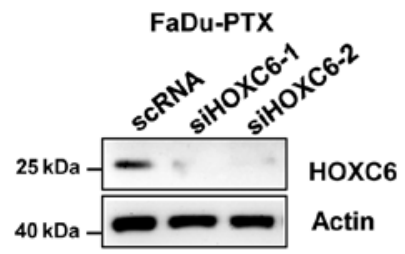

B

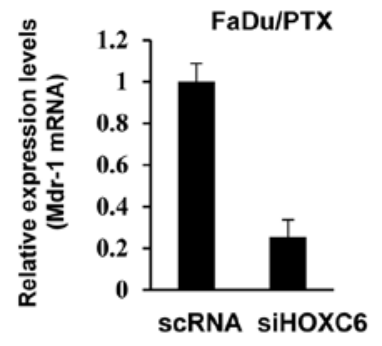

C

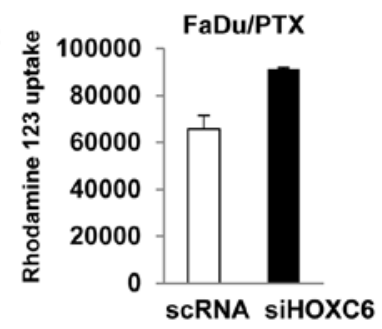

D
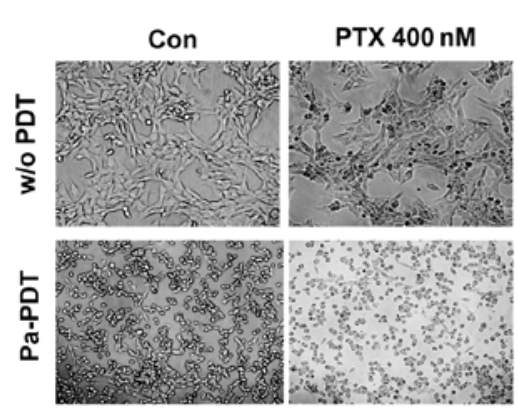
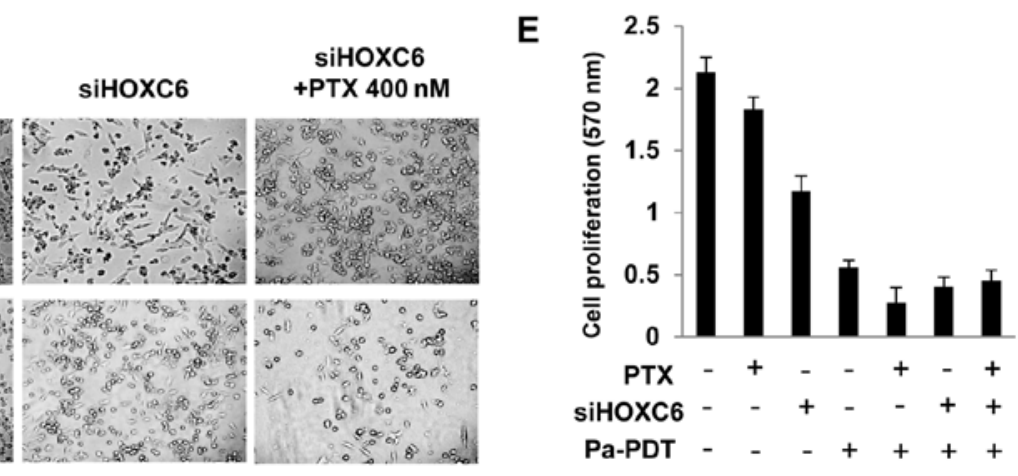

Figure 6. Downregulation of HOXC6 sensitizes FaDu-PTX cells to Pa-PDT. (A) The cells were transfected with either HOXC6 siRNA (20 nM) or control scRNA. After $48 \mathrm{~h}$, the cells were collected, and total cellular proteins were used for western blot analysis with antiHOXC6 antibody as previously described. (B) The MDR-1 mRNA levels were analyzed by RT-PCR. (B) FaDu-PTX cells were transfected with either scramble siRNA or siHOXC6 for 48 h. The MDR-1 mRNA levels in these cells were assessed using RT-PCR analysis. The expression levels were normalized to GAPDH. (C) Representative drug uptake is shown depicting the levels of Rho123 accumulation in FaDu-PTX cells that were transfected for $48 \mathrm{~h}$ with either HOXC6 siRNA or control scramble siRNA. After $48 \mathrm{~h}$, the results of three experiments were summarized. (D and E) Morphological changes in FaDu-PTX cells after siHOXC6 transfection either with or without Pa-PDT treatment. Images were taken with a phase contrast microscope at x100 magnification. Cell viability was assessed using the MTT assay in the presence of Pa-PDT $\left(0.2 \mu \mathrm{M}, 1.2 \mathrm{~J} / \mathrm{cm}^{2}\right)$ in FaDu-PTX cells transfected with HOXC6 siRNA.

in FaDu-PTX cells (Fig. 5C). However, no significant expression of MDR-1 proteins was observed in the FaDu cells.

To determine the effects of Pa-PDT on the AKT/mTOR/ p70S6K signaling pathway, cells were treated with Pa-PDT, and lysates were collected at $6 \mathrm{~h}$ after treatment and examined by western blot analysis. These experiments revealed that Pa-PDT treatment inhibited AKT/mTOR/p70S6K signaling in FaDu-PTX cells, as indicated by the reduced levels of p-AKT 

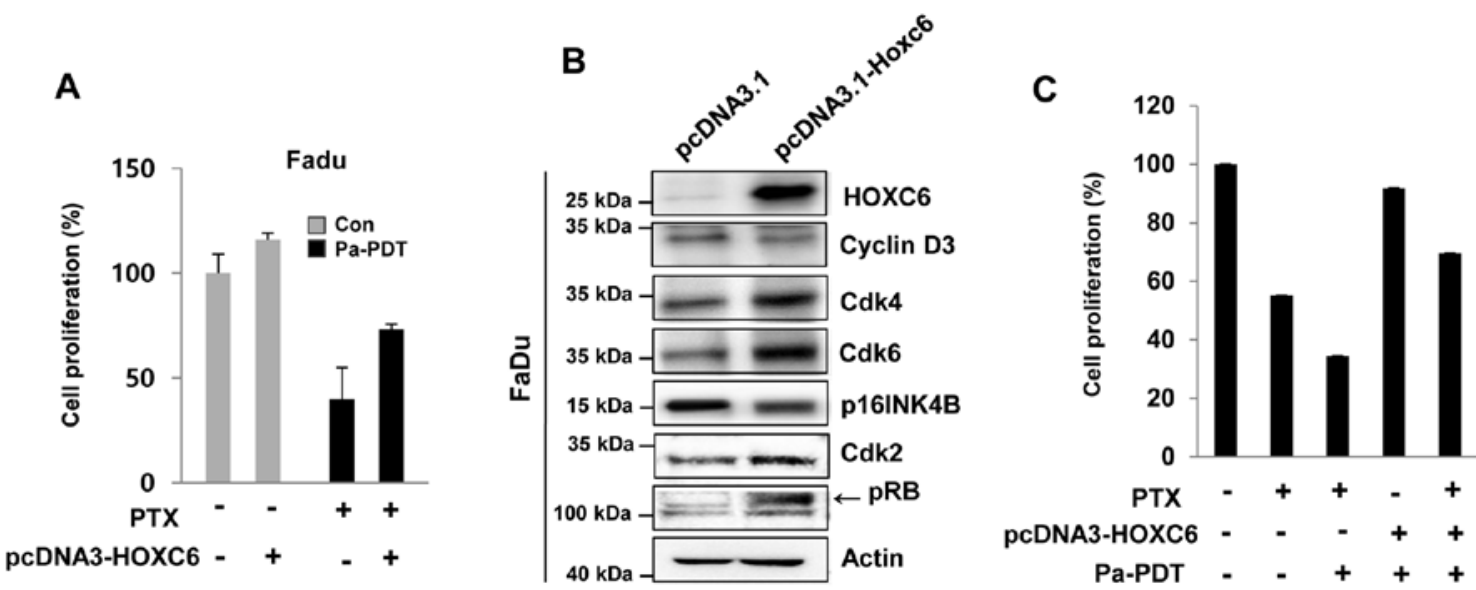

Figure 7. HOXC6 regulates the cell growth and expression of CDKs. (A) Effects of HOXC6 on cell proliferation in FaDu cells. The cells were transiently transfected with the pcDNA3-HOXC6 plasmid for $24 \mathrm{~h}$ and treated with paclitaxel $(400 \mathrm{nM})$ for $24 \mathrm{~h}$ before measuring cell proliferation using the MTT assay. (B) The effect of HOXC6 on cell cycle progression. FaDu cells were transfected with pcDNA3-HOXC6 plasmid for $48 \mathrm{~h}$, and cell cycle regulatory proteins were assessed by western blot analysis. (C) Cell viability was assessed by the MTT assay FaDu cells transfected with HOXC6 and in the presence of either paclitaxel (400 nM) or Pa-PDT treatment.

and p-p70S6K. p-ERK1/2 had similar expression trends as AKT and p70S6K. However, the expression of p53 and p21 did not affect Pa-PDT-treated FaDu-PTX cells (Fig. 5D). Combined with the strong inhibition of HOXC6 and MDR-1 in Pa-PDT-treated FaDu-PTX cells, these results suggested that MDR-1 may be correlated with HOXC6 and/or the AKT/mTOR signaling pathway in PDT-treated MDR cancer cells.

HOXC6 siRNA induces drug sensitivity and Pa-PDT mediated apoptosis in FaDu/PTX cells. To determine the effect of HOXC6 siRNA, we determined the drug sensitivity in FaDu-PTX cells. Western blotting showed that HOXC6 expression was decreased in siHOXC6-transfected FaDu-PTX cells (Fig. 6A). HOXC6 siRNA inhibited MDR-1 mRNA expression compared with scramble siRNA-transfected cells (Fig. 6B). Rho123 accumulation analysis confirmed that Rho123 accumulation increased in siHOXC6-transfected cells compared with the scRNA control (Fig. 6C).

Next, we treated FaDu-PTX cells with either a non-toxic dose of paclitaxel $(400 \mathrm{nM})$ or HOXC6 siRNA followed by treatment either with or without Pa-PDT. We then tested Pa-PDT sensitivity by observing changes in cell proliferation. The MTT assay indicated that the proliferation/viability of FaDu-PTX cells was slightly decreased by paclitaxel compared with untreated cells. Either HOXC6 siRNA or Pa-PDT treatment inhibited FaDu-PTX cell viability compared with the control-treated cells. Notably, treatment with either paclitaxel or siHOXC6 combined with Pa-PDT significantly inhibited cell proliferation compared with siHOXC6 or paclitaxel alone. Furthermore, the FaDu-PTX cells receiving Pa-PDT had similar results between the paclitaxel and siHOXC6 treatment groups (Fig. 6D and 6E).

Reversal of Pa-PDT sensitivity in FaDu cells by HOXC6 overexpression. The HOXC6 was found to be less inducible in FaDu cells compared with to FaDu-PTX cells. Thus, we examined the effect of HOXC6 overexpression in FaDu cells, which showed strong sensitivity to paclitaxel due to a low induction of MDR-1. HOXC6 overexpression conferred paclitaxel resistance to FaDu cells (Fig. 7A). HOXC6 overexpression was confirmed by immunoblot assay (Fig. 7B). Notably, a remarkable difference between mock-transfected cells and HOXC6-overexpressing $\mathrm{FaDu}$ cells was also observed regarding the expression of cell cycle regulatory proteins. The HOXC6-overexpressing FaDu cells revealed that HOXC6 induced the expression of CDK4, CDK6 and CDK2, whereas HOXC6 overexpression importantly inhibited the cell cycle negative regulators p16 and phospho-RB (Fig. 7B).

We also investigated the effect of either paclitaxel or Pa-PDT on the overexpression of HOXC6 in FaDu cells. As expected, we detected remarkable inhibition of cell proliferation with paclitaxel and/or Pa-PDT cell treatment (Fig. 7B). However, Pa-PDT- and/or paclitaxel-induced cell growth inhibition was restrained by the overexpression of HOXC6, which conferred resistance to paclitaxel and/or Pa-PDT (Fig. 7C).

The effect of HOXC6 depletion and Pa-PDT in a FaDu-PTX xenograft mouse model. In support of the identified HOXC6dependent effects on multidrug resistance in vitro, a tumor xenograft model was used to examine the alterations in the pathological characteristics in vivo by modifying HOXC6 transcription. $\mathrm{C} 3 \mathrm{H}$ mice were randomized and subcutaneously engrafted with FaDu-PTX cells treated in vitro with either HOXC6 siRNA or Pa-PDT. The xenograft mice injected with HOXC6-deficient cells strongly showed a condensed tumor mass and induced susceptibility to apoptosis. Pa-PDT also reduced the tumor size and increased cell death in the xenograft tumor (Fig. 8A-C). No systemic toxicity (including the body weight changes or other apparent adverse effects) was observed in the animals throughout the study period (data not shown). Specifically, PCNA expression, a marker of cell proliferation, was decreased in implanted tumors derived from cells treated with either HOXC6 siRNA or Pa-PDT compared with the control or PTX-treated groups (Fig. 8D). We next assessed the levels of HOXC6 mRNA in tumor tissue. 
A

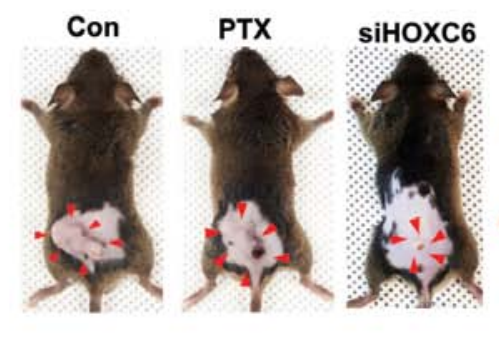

B

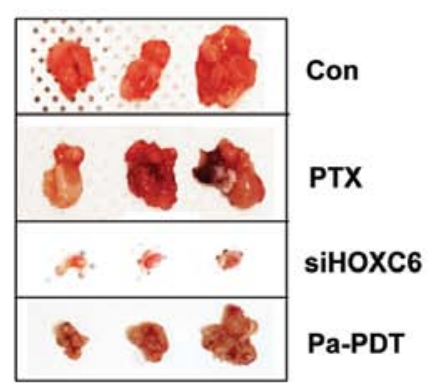

D

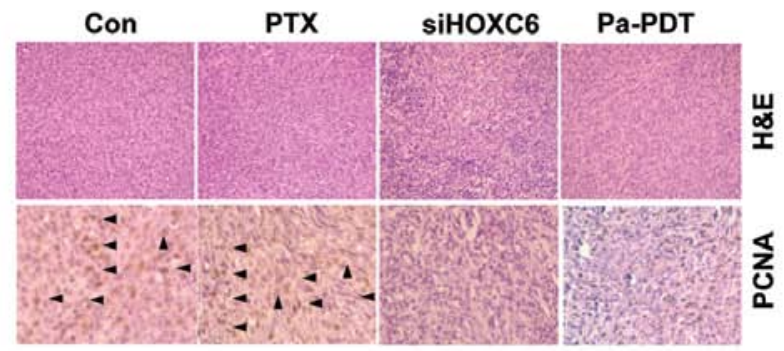

E
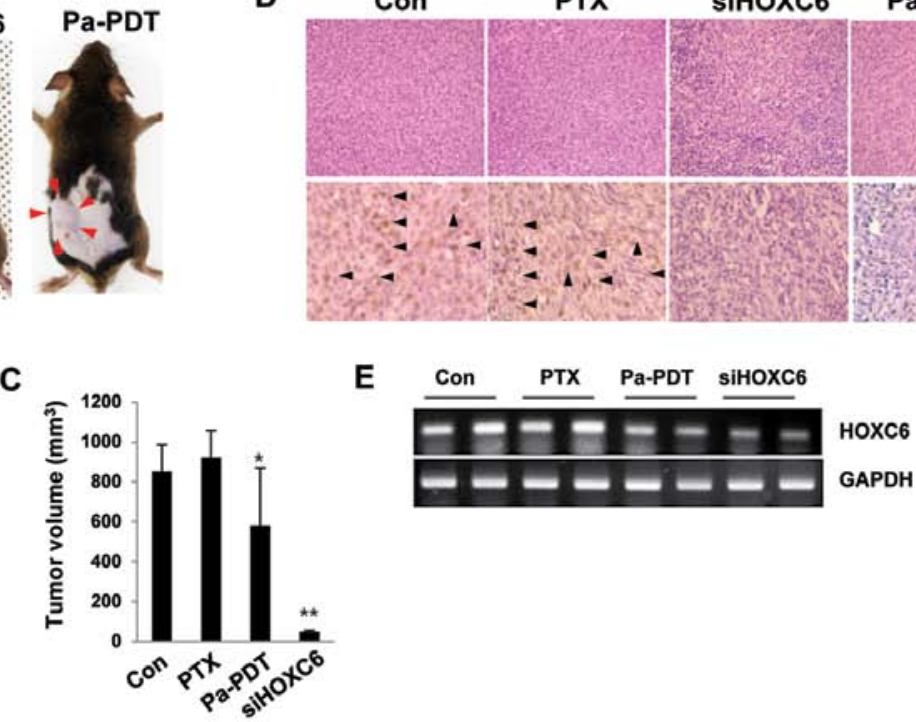

Figure 8. siHOXC6 inhibits tumor growth in vivo. FaDu-PTX cells were transfected with either HOXC6 siRNA (20 nM) for $48 \mathrm{~h}$ or treated with Pa-PDT $\left(0.2 \mu \mathrm{M}, 1.2 \mathrm{~J} / \mathrm{cm}^{2}\right)$ for $24 \mathrm{~h}$. Cells $\left(3 \times 10^{6}\right.$ per mouse) were injected subcutaneously into the left flank of C3H mice. (A-C) Tumor volume was measured at 14 days and calculated using the formula $\mathrm{V}=\left(\mathrm{ab}^{2}\right) / 2$, in which a is the largest diameter and $\mathrm{b}$ is the shortest diameter of the tumor. ${ }^{*} \mathrm{P}<0.05$, ${ }^{* *} \mathrm{P}<0.01$ compared to untreated control. (D) H\&E staining of tumor sections. Immunohistochemistry for PCNA was performed on paraffin-embedded sections from the tumor. (E) HOXC6 mRNA expression was verified by RT-PCR from mouse tumor tissue.

As expected, HOXC6 mRNA was strongly expressed in the control and paclitaxel-treated groups but weakly expressed in the siHOXC6- and Pa-PDT-treated groups (Fig. 8E). These data confirmed that the described genetic and other substantial factors affecting HOXC6 transcription directly affect the tumor progression/proliferation of multidrug-resistant cancer cells, specifically PTX-resistant tumors.

\section{Discussion}

In this study, the cytotoxicity of Pa-PDT was measured in the human oral cancer cell lines YD-5, YD10B, YD-15 and FaDu, as well as the MDR line FaDu-PTX. Pa-PDT significantly inhibited cell proliferation of human oral cancer cells; however, there was no cytotoxicity in either Pa- or light-treated cells. This result is consistent with our previous finding in skin and lung cancer cells. We first observed that Pa-PDT predominantly inhibited cell growth and induced apoptosis in FaDu-PTX cells as indicated by multiple independent approaches that revealed either the expression of apoptosis-specific proteins or the formation of pro-apoptotic morphology.

Because ROS is critical for cell death induced by PDT, we examined ROS production by Pa-PDT in FaDu and FaDu-PTX cells. Fluorescent scanning analysis showed that Pa-PDT led to intracellular ROS production in both cell lines. However, ROS production was highly induced after Pa-PDT treatment in the FaDu cells compared with the FaDu-PTX cells. From these data, we speculated that FaDu-PTX cells had lower ROS levels compared to its parental cell line due to MDR-1 overexpression. However, our results proved that $\mathrm{FaDu}$ and FaDu-PTX cell lines exhibited similar cell death by Pa-PDT treatment. These findings indicated that the cell death of $\mathrm{FaDu}$ and FaDu-PTX cells due to Pa-PDT-induced photocytotoxicity was not attributed to the difference in intracellular ROS levels.
One possible explanation for this might be the altered genetic factors in MDR cells (5-10).

The mechanisms underlying the MDR response are less clear in oral cancer than in other tumor types (39). We used quantitative real-time PCR to investigate changes in the expression profile of MDR signaling pathway-related genes between FaDu and FaDu-PTX cells. Compared with the parental FaDu cells, 10 genes that were upregulated $>2$-fold (HOXA1, HOXA10, HOXB4, HOXC6, MMP-2, -3, -7, -9, Notch-1 and Notch-3) and 3 genes that were more downregulated (HOXA10, HOXA7 and HOXB2) were found in the FaDu-PTX cells. Moreover, we previously demonstrated that HOXC6 plays an important role in the process of MDR. Although the expression of HOXA1, HOXA10, HOXB4, HOXC6, MMP-2, -3, -7, -9, Notch-1 and Notch-3 was beyond our expectations, they may be involved in complicated regulatory mechanisms with regard to MDR-related genes. Several studies have demonstrated that activation of Notch signaling contributes to the MDR regulatory mechanism $(35,40)$. It has been demonstrated that $\mathrm{UPAR}$, a serine proteinase receptor, is also correlated with the drug resistance-related gene multidrug resistance-1 (MDR-1). In addition, matrix metalloproteinase genes (including MMP-2 and MMP-9) are reported to be involved in MDR-1 expression $(41,42)$.

As multiple factors may contribute to chemoresistance, the cell survival and apoptotic signaling pathways determining the susceptibility of cells to chemotherapy appear to be important in MDR. However, detailed mechanisms on how cancer cells upregulate drug resistance-related genes and evolve the ability to resist apoptotic stimuli by anticancer drugs remain poorly understood. This requires further studies.

The PI3K/Akt/mTOR pathway plays a major role in cell survival, proliferation and angiogenesis in human cancer. Recently, the role of the PI3K/Akt/mTOR pathway in chemo- 
resistance has been discussed $(36,37)$. It has been reported that inhibition of the PI3K/Akt/mTOR pathway results in autophagy and induction of apoptosis as well as the restoration of drug sensitivity in chemoresistant cancers (36).

In this study, we found that Pa-PDT induces FaDu-PTX cell apoptosis by inhibiting AKT and mTOR target proteins such as p70S6K phosphorylation, which was detected by western blotting. In addition, we found that Pa-PDT decreases $p$-ERK1/2 levels, which play an important role in antiproliferative and pro-apoptotic activities. The ERK1/2 MAPK also controls various cell responses, such as proliferation, migration, and differentiation depending on the cell type and stimulus (43). Thus, Pa-PDT-selective targeting of the Akt/mTOR/ERK signaling pathway to induce apoptosis may be beneficial in the overcoming chemoresistance of oral cancer.

p53/p21 is a key tumor suppressor pathway that is trigged by various cell responses, including DNA damage and has been implicated in tumor suppression (38). In this study, we examined whether the $\mathrm{p53/p} 21$ pathway is involved in the tumor suppression induced by Pa-PDT in FaDu and FaDu-PTX cells. We found that Pa-PDT in FaDu cells resulted in decreased p53 and p21 expression. In the FaDu-PTX cells, no detectable expression of p53 and p21 was seen. These data suggest that the cytotoxicity of Pa-PDT is linked to changes in the p53/p21 pathway in FaDu cells but not in FaDu-PTX cells. The reason for the difference of the molecular mechanism involved in the cellular Pa-PDT response between FaDu and FaDu-PTX cells is unclear. However, the mechanism of action of Pa-PDT might depend on the subcellular localization and molecular targets of the photosensitizer, the metabolic potential and the genotype of the tumor cell type.

The present study correlated chemoresistance in oral cancer cell lines with the HOX family, HOXC6 in particular. The expression of HOXC6 was upregulated in MDR cell lines, including FaDu-PTX, MCF-7/ADR and SNU601/CIS cells (10). Moreover, using gene transfection and RNA interference techniques, we demonstrated that the in vitro drug sensitivity to paclitaxel and chemotherapeutic drug-induced apoptosis in FaDu-PTX cells were increased in cells transfected with siHOXC6. This strongly indicates that HOXC6 is involved in the regulation of MDR in MDR cancer cells. In addition, we demonstrated that the expression of MDR-1 was regulated by HOXC6. As mentioned above, the HOXC6 signaling pathway regulates a variety of cellular processes, including cell maintenance, cellular differentiation, proliferation, and apoptosis, as a versatile signaling orchestrator; HOXC6 expression has been implicated in the development of various cancers (including oral cancer) (24-33). We presumed that HOXC6 could be a candidate molecule for determining MDR sensitivity to Pa-PDT. In this study, HOXC6 and MDR-1 expression were increased more in FaDu-PTX cells compared to FaDu cells. HOXC6 and MDR-1 were downregulated after Pa-PDT treatment in FaDu-PTX cells. In addition, we demonstrated that siRNA targeting HOXC6 led to the efficient and specific inhibition of endogenous MDR-1 mRNA and Rho123 accumulation in FaDu-PTX cells. These findings suggest a possible inhibition of the HOXC6/MDR-1 signaling pathway after treatment with Pa-PDT.

We also found that downregulation of HOXC6 reversed chemoresistance and inhibited cell proliferation of FaDu-PTX cells in vitro. More importantly, HOXC6 overexpression inhibited Pa-PDT-mediated cell growth inhibition as well as the upregulation of the expression of cell cycle-related proteins, including $\mathrm{Cdk} 4, \mathrm{Cdk} 6$ and $\mathrm{Cdk} 2$. This provided new evidence that Pa-PDT affected HOXC6, which could become a promising gene target. In support of the identified HOXC6-dependent effects on multidrug resistance in vitro, a tumor xenograft model was used to examine the probable physiological alteration of drug-resistant tumors by modifying HOXC6 transcription. Both HOXC6-deficient and Pa-PDT treated tumors showed a less condensed tumor mass and increased susceptibility to apoptosis. Additionally, although the HOXC6 siRNA and Pa-PDT treatment inhibited the growth of FaDu-PTX cells in vitro and in vivo, the level of cell growth inhibition was different. The differential cytotoxicity between siHOXC6 and Pa-PDT might be due to the different inhibition levels of either HOXC6 or its targets. Western blot analysis showed that siHOXC6 had a greater effect in reducing the levels of HOXC6 compared to the Pa-PDT treatment. The inhibition levels of HOXC6 may be a result of the alternations in the tumor growth or an MDR mechanism that renders the cells more sensitive to either Pa-PDT or anticancer drug. The results suggest that HOXC6 could be a new target in treating MDR oral cancer.

In conclusion, our findings provide the first evidence that Pa-PDT could decrease tumor growth via inhibition of the HOXC6/MDR-1-mediated pathway. This inhibition may increase susceptibility to cell death by enhancing the effects of intracellular paclitaxel or other anticancer drug levels in MDR human oral tumor cells, which would overcome the difficulty in treating this disease in patients.

\section{Acknowledgements}

The present study was supported by the Basic Science Research Program through the National Research Foundation of Korea (NRF) funded by the Ministry of Science, ICT and Future Planning (no. 2015005588) and funded by the Korean government MSIP (no. 2008-0062283).

\section{References}

1. Gottesman MM, Fojo T and Bates SE: Multidrug resistance in cancer: Role of ATP-dependent transporters. Nat Rev Cancer 2: 48-58, 2002.

2. Baguley BC: Multidrug resistance in cancer. Methods Mol Biol 596: 1-14, 2010.

3. Haimeur A, Conseil G, Deeley RG and Cole SP: The MRP-related and BCRP/ABCG2 multidrug resistance proteins: Biology, substrate specificity and regulation. Curr Drug Metab 5: 21-53, 2004.

4. Redmond KM, Wilson TR, Johnston PG and Longley DB: Resistance mechanisms to cancer chemotherapy. Front Biosci 13: 5138-5154, 2008.

5. Szakács G, Annereau JP, Lababidi S, Shankavaram U, Arciello A, Bussey KJ, Reinhold W, Guo Y, Kruh GD, Reimers M, et al: Predicting drug sensitivity and resistance: Profiling ABC transporter genes in cancer cells. Cancer Cell 6: 129-137, 2004.

6. Deeley RG and Cole SP: Substrate recognition and transport by multidrug resistance protein 1 (ABCC1). FEBS Lett 580: 1103-1111, 2006.

7. Litman T, Druley TE, Stein WD and Bates SE: From MDR to MXR: New understanding of multidrug resistance systems, their properties and clinical significance. Cell Mol Life Sci 58: 931-959, 2001. 
8. Baguley BC: Multiple drug resistance mechanisms in cancer. Mol Biotechnol 46: 308-316, 2010.

9. Pang A, Au WY and Kwong YL: Caveolin-1 gene is coordinately regulated with the multidrug resistance 1 gene in normal and leukemic bone marrow. Leuk Res 28: 973-977, 2004.

10. Kim KJ, Moon SM, Kim SA, Kang KW, Yoon JH and Ahn SG: Transcriptional regulation of MDR-1 by HOXC6 in multidrugresistant cells. Oncogene 32: 3339-3349, 2013.

11. Chen J, Keltner L, Christophersen J, Zheng F, Krouse M, Singhal A and Wang SS: New technology for deep light distribution in tissue for phototherapy. Cancer J 8: 154-163, 2002.

12. Dolmans DE, Fukumura D and Jain RK: Photodynamic therapy for cancer. Nat Rev Cancer 3: 380-387, 2003.

13. Kessel D and Erickson C: Porphyrin photosensitization of multidrug resistant cell types. Photochem Photobiol 55: 397-399, 1992.

14. Lu HL, Syu WJ, Nishiyama N, Kataoka K and Lai PS: Dendrimer phthalocyanine-encapsulated polymeric micellemediated photochemical internalization extends the efficacy of photodynamic therapy and overcomes drug-resistance in vivo. J Control Release 155: 458-464, 2011.

15. Gulati SC, Lemoli RM, Igarashi T and Atzpodien J: Newer options for treating drug-resistant (MDR+) cancer cells using photoradiation therapy. Leuk Lymphoma 12: 427-433, 1994.

16. Yoon HE, Oh SH, Kim SA, Yoon JH and Ahn SG: Pheophorbide a-mediated photodynamic therapy induces autophagy and apoptosis via the activation of MAPKs in human skin cancer cells. Oncol Rep 31: 137-144, 2014.

17. Ahn MY, Yoon HE, Kwon SM, Lee J, Min SK, Kim YC, Ahn SG and Yoon JH: Synthesized pheophorbide a-mediated photodynamic therapy induced apoptosis and autophagy in human oral squamous carcinoma cells. J Oral Pathol Med 42: 17-25, 2013.

18. Ahn MY, Kwon SM, Kim YC, Ahn SG and Yoon JH: Pheophorbide a-mediated photodynamic therapy induces apoptotic cell death in murine oral squamous cell carcinoma in vitro and in vivo. Oncol Rep 27: 1772-1778, 2012.

19. Tang PM, Chan JY, Au SW, Kong SK, Tsui SK, Waye MM, Mak TC, Fong WP and Fung KP: Pheophorbide a, an active compound isolated from Scutellaria barbata, possesses photodynamic activities by inducing apoptosis in human hepatocellular carcinoma. Cancer Biol Ther 5: 1111-1116, 2006.

20. Tang PM, Zhang DM, Xuan NH, Tsui SK, Waye MM, Kong SK, Fong WP and Fung KP: Photodynamic therapy inhibits P-glycoprotein mediated multidrug resistance via JNK activation in human hepatocellular carcinoma using the photosensitizer pheophorbide a. Mol Cancer 8: 56-66, 2009.

21. Hajri A, Wack S, Meyer C, Smith MK, Leberquier C, Kedinger M and Aprahamian M: In vitro and in vivo efficacy of photofrin and pheophorbide a, a bacteriochlorin, in photodynamic therapy of colonic cancer cells. Photochem Photobiol 75: 140-148, 2002

22. Jin ZH, Miyoshi N, Ishiguro K, Umemura S, Kawabata K, Yumita N, Sakata I, Takaoka K, Udagawa T, Nakajima S, et al: Combination effect of photodynamic and sonodynamic therapy on experimental skin squamous cell carcinoma in $\mathrm{C} 3 \mathrm{H} / \mathrm{HeN}$ mice. J Dermatol 27: 294-306, 2000

23. Bui-Xuan NH, Tang PM, Wong CK and Fung KP: Photo-activated pheophorbide-a, an active component of Scutellaria barbata, enhances apoptosis via the suppression of ERK-mediated autophagy in the estrogen receptor-negative human breast adenocarcinoma cells MDA-MB-231. J Ethnopharmacol 131: 95-103, 2010.

24. Bodey B, Bodey B Jr, Siegel SE and Kaiser HE: Immunocytochemical detection of the homeobox B3, B4, and C6 gene products in breast carcinomas. Anticancer Res 20 (5A): 3281-3286, 2000

25. Castronovo V, Kusaka M, Chariot A, Gielen J and Sobel M: Homeobox genes: Potential candidates for the transcriptional control of the transformed and invasive phenotype. Biochem Pharmacol 47: 137-143, 1994.
26. Fujiki K, Duerr EM, Kikuchi H, Ng A, Xavier RJ, Mizukami Y, Imamura T, Kulke MH and Chung DC: Hoxc6 is overexpressed in gastrointestinal carcinoids and interacts with JunD to regulate tumor growth. Gastroenterology 135: 907-916, 916.e1-916.e2, 2008.

27. Bodey B, Bodey B Jr, Siegel SE, Luck JV and Kaiser HE: Homeobox B3, B4, and C6 gene product expression in osteosarcomas as detected by immunocytochemistry. Anticancer Res 20: 2717-2721, 2000

28. Miller GJ, Miller HL, van Bokhoven A, Lambert JR, Werahera PN, Schirripa O, Lucia MS and Nordeen SK: Aberrant HOXC expression accompanies the malignant phenotype in human prostate. Cancer Res 63: 5879-5888, 2003.

29. McCabe CD, Spyropoulos DD, Martin D and Moreno CS: Genome-wide analysis of the homeobox C6 transcriptional network in prostate cancer. Cancer Res 68: 1988-1996, 2008.

30. Grishina IB, Kim SY, Ferrara C, Makarenkova HP and Walden PD: BMP7 inhibits branching morphogenesis in the prostate gland and interferes with Notch signaling. Dev Biol 288: 334-347, 2005.

31. Ricort JM and Binoux M: Insulin-like growth factor-binding protein-3 activates a phosphotyrosine phosphatase. Effects on the insulin-like growth factor signaling pathway. J Biol Chem 277: 19448-19454, 2002.

32. van der Geer P, Hunter T and Lindberg RA: Receptor proteintyrosine kinases and their signal transduction pathways. Annu Rev Cell Biol 10: 251-337, 1994.

33. Lin Y, Liu G, Zhang Y, Hu YP, Yu K, Lin C, McKeehan K, Xuan JW, Ornitz DM, Shen MM, et al: Fibroblast growth factor receptor 2 tyrosine kinase is required for prostatic morphogenesis and the acquisition of strict androgen dependency for adult tissue homeostasis. Development 134: 723-734, 2007.

34. Moon SM, Kim SA, Yoon JH and Ahn SG: HOXC6 is deregulated in human head and neck squamous cell carcinoma and modulates Bcl-2 expression. J Biol Chem 287: 35678-35688, 2012.

35. Cho S, Lu M, He X, Ee PL, Bhat U, Schneider E, Miele L and Beck WT: Notch1 regulates the expression of the multidrug resistance gene ABCC1/MRP1 in cultured cancer cells. Proc Natl Acad Sci USA 108: 20778-20783, 2011.

36. Chiu LY, Hu ME, Yang TY, Hsin IL, Ko JL, Tsai KJ and Sheu GT: Immunomodulatory protein from ganoderma microsporum induces pro-death autophagy through Akt-mTOR-p70S6K pathway inhibition in multidrug resistant lung cancer cells. PLoS One 10: e0125774, 2015.

37. Galoian K, Temple HT and Galoyan A: mTORC1 inhibition and ECM-cell adhesion-independent drug resistance via PI3K-AKT and PI3K-RAS-MAPK feedback loops. Tumour Biol 33: 885-890, 2012.

38. Ye S, Shen J, Choy E, Yang C, Mankin H, Hornicek F and Duan Z: p53 overexpression increases chemosensitivity in multidrug-resistant osteosarcoma cell lines. Cancer Chemother Pharmacol 77: 349-356, 2016.

39. Yajima T, Ochiai H, Uchiyama T, Takano N, Shibahara T and Azuma T: Resistance to cytotoxic chemotherapy-induced apoptosis in side population cells of human oral squamous cell carcinoma cell line Ho-1-N-1. Int J Oncol 35: 273-280, 2009.

40. Yan S, Ma D, Ji M, Guo D, Dai J, Zhao P and Ji C: Expression profile of Notch-related genes in multidrug resistant K562/A02 cells compared with parental K562 cells. Int J Lab Hematol 32: 150-158, 2010

41. Zhou H, Tang Y, Liang X, Yang X, Yang J, Zhu G, Zheng M and Zhang C: RNAi targeting urokinase-type plasminogen activator receptor inhibits metastasis and progression of oral squamous cell carcinoma in vivo. Int J Cancer 125: 453-462, 2009.

42. Yang JM, Xu Z, Wu H, Zhu H, Wu X and Hait WN: Overexpression of extracellular matrix metalloproteinase inducer in multidrug resistant cancer cells. Mol Cancer Res 1: 420-427, 2003.

43. Liu QH, Shi ML, Sun C, Bai J and Zheng JN: Role of the ERK1/2 pathway in tumor chemoresistance and tumor therapy. Bioorg Med Chem Lett 25: 192-197, 2015. 